\title{
PREVALENSI GIARDIASIS DAN KONDISI HYGIENE PERORANGAN PADA MURID PAUD DI KB-TK AL AMIN PACIRAN LAMONGAN
}

\section{Prevalence of Giardiasis and Personal Hygiene Conditions in Pre-School Students in KB-TK Al Amin Paciran Lamongan}

\author{
Dwi Septia Nengsih ${ }^{1}$, Sigit Ari Saputro ${ }^{2}$, Khuliyah Candraning Diyanah ${ }^{1}$ \\ ${ }^{1}$ Departemen Kesehatan Lingkungan Fakultas Kesehatan Masyarakat Universitas Airlangga \\ ${ }^{2}$ Departemen Biostatistika dan Kependudukan Fakultas Kesehatan Masyarakat Universitas Airlangga \\ Email: k.c.diyanah@fkm.unair.ac.id
}

Diterima: 2 Maret 2020; Direvisi: 7 Juni 2020; Disetujui: 23 September 2020

\begin{abstract}
Small intestine infection caused by Giardia lamblia (giardiasis) occurs mostly in children living in developing country with poor sanitation. This study aims to determine the risk of giardiasis and personal hygiene conditions in pre-school students at KB-TK Al Amin Paciran Lamongan aged 2-6 years. Number of samples were 61 students, the dependent variable was the incidence of giardiasis, and independent variable was personal hygiene including nail hygiene, hand washing habit, footwear habit, and defecating habits. The result showed that 5 out of 61 students (8,2\%) were infected with Giardia lamblia. All children (100\%) with giardiasis had poor nail hygiene, footwear habit, and defecating habit. As many as $80 \%$ of students with giardiasis have poor handwashing habits. Students with poor footwear habit $(O R=43,71$; 95\% CI 3,98-2046,9); open defecation habits (OR=13,33; 95\% CI 1,40-628,05); poor nail hygiene (OR=12,31; 95\% CI 1,29-580,49); poor hand washing habits (OR=5,73; 95\% CI 0,5-290,96) had a greater risk of developing giardiasis. Supervision and healthy behavior are highly recommended, including using footwear when playing on the ground, defecating in the latrine, maintaining nail hygiene, and washing hands with soap before eating or after defecating.
\end{abstract}

Keywords: Prevalence, giardiasis, personal hygiene, pre-school students

\begin{abstract}
ABSTRAK
Infeksi usus halus disebabkan oleh Giardia lamblia (giardiasis) banyak terjadi pada anak-anak yang tinggal di negara berkembang dengan tingkat sanitasi buruk. Penelitian ini bertujuan untuk mengetahui risiko terjadinya giardiasis dan kondisi hygiene perorangan pada murid PAUD di KB-TK Al Amin Paciran Lamongan usia 2-6 tahun. Jumlah sampel adalah 61 murid, variabel dependen adalah kejadian giardiasis, dan variabel independen adalah hygiene perorangan meliputi kebersihan kuku, kebiasaan mencuci tangan, kebiasaan menggunakan alas kaki, dan kebiasaan buang air besar (BAB). Hasil penelitian menunjukkan bahwa 5 dari 61 murid (8,2\%) terinfeksi Giardia lamblia. Seluruh murid (100\%) dengan giardiasis mempunyai kebersihan kuku, kebiasaan menggunakan alas kaki dan kebiasaan BAB yang kurang baik. Sebanyak $80 \%$ murid dengan giardiasis mempunyai kebiasaan mencuci tangan yang kurang baik. Murid dengan kebiasaan menggunakan alas kaki kurang baik (OR=43,71; 95\% CI 3,98-2046,9); kebiasaan BAB sembarangan $(\mathrm{OR}=13,33$; 95\% CI 1,40-628,05); kebersihan kuku kurang baik (OR=12,31; 95\% CI 1,29580,49); kebiasaan mencuci tangan yang kurang baik $(\mathrm{OR}=5,73$; 95\% CI 0,5-290,96) mempunyai risiko lebih besar terkena giardiasis. Pengawasan dan berperilaku hidup sehat sangat dianjurkan antara lain menggunakan alas kaki ketika bermain di tanah, membiasakan BAB di jamban, menjaga kebersihan kuku, dan mencuci tangan dengan sabun sebelum makan atau setelah buang air besar.
\end{abstract}

Kata kunci: Prevalensi, giardiasis, hygiene perorangan, murid PAUD

\section{PENDAHULUAN}

Infeksi usus halus yang disebabkan oleh parasit protozoa yaitu Giardia lamblia (Giardia intestinalis atau Giardia duo denalis) biasa disebut dengan giardiasis. Jenis protozoa tersebut dapat dijumpai di saluran cerna berbagai macam mamalia termasuk manusia (Leung et al., 2019). 
berkisar antara $20-30 \%$ di $\quad \begin{array}{r}\text { Prevalensi } \\ \text { giardiasis umumnya }\end{array}$ berkembang dan $3-7 \%$ di negara maju (Mauludyahwati et al., 2018). Karena tidak menunjukan gejala, 50-75\% infeksi Giardia sering kali tidak dilaporkan (Leung et al., 2019). Giardiasis lebih banyak dialami oleh anak-anak dibandingkan orang dewasa. Giardiasis umumnya terjadi pada anak usia 1 -9 tahun (Centers for Disease Control and Prevention, 2015), hampir $100 \%$ anak-anak umur 1 sampai 2 tahun di negara berkembang mendapatkan infeksi Giardia lamblia (Ivanov, 2010).

Giardiasis adalah salah satu penyebab morbiditas dan mortalitas pada masyarakat yang tinggal di daerah dengan sanitasi buruk (Mauludyahwati dkk., 2018). Faktor penyebab giardiasis dapat berupa faktor lingkungan maupun faktor perilaku. Faktor lingkungan ialah seperti sumber air yang tercemar feses atau limbah, kurangnya akses air bersih dan jamban maupun perpindahan kista giardia melalui vektor serangga (Ramadhan, 2019). Faktor perilaku penyebab giardiasis yaitu kebiasaan mencuci tangan dan memotong kuku yang kurang baik (Artika, Nurhayati and Alioes, 2017).

Giardiasis dapat ditularkan melalui fecal oral maupun secara tidak langsung melalui air yang terkontaminasi tinja manusia atau hewan yang mengandung kista Giardia Lamblia karena hygiene yang rendah (Artika, Nurhayati dan Alioes, 2017).

Infeksi Giardia lamblia dapat terjadi jika kista dari parasit di lingkungan tertelan, sampai pada saluran lambung trofozoit akan masuk ke dalam lingkungan yang kurang asam dan empedu pada usus halus bagian atas (Bartelt and Sartor, 2015).

Penderita giardiasis dapat mengalami diare akut hingga kronis. Berdasarkan data dari World Health Organization (WHO) pada tahun 2015, sebanyak 1,7 miliar kasus diare terjadi pada anak balita dengan angka kematian sekitar 525.000 setiap tahunnya (Anzani and Saftarina, 2019). Berdasarkan hasil Riset Kesehatan Dasar (Riskesdas) pada tahun 2018 didapatkan bahwa prevalensi diare pada balita dari tahun 2013 hingga
2018 cenderung naik yaitu sebesar 12,3\% menjadi 18,5\% (Kementerian Kesehatan RI Badan Penelitian dan Pengembangan, 2018).

Selain diare akut dan kronis, manifestasi klinis lainnya dari infeksi ini asimtomatik, berupa malabsorbsi yang berdampak pada penurunan berat badan. Kondisi asimtomatik dapat dipengaruhi oleh berbagai faktor seperti, status imun dan nutrisi serta dosis infeksi (Halliez and Buret, 2013). Akibat dari infeksi ini juga dapat menyebabkan keterlambatan perkembangan psikomotorik, dapat menyebabkan defisiensi besi dan gangguan perkembangan pada anak (Saraswati dan Nurdian, 2018).

Giardiasis merupakan gangguan infeksi parasit pada usus halus bagian atas yang dapat menimbulkan gejala pada intestinal maupun ekstraintestinal. Jika timbul gejala biasanya masa inkubasi giardiasis adalah antara $9-15$ hari. Gejala intestinal muncul satu hingga dua minggu setelah kontak dengan protozoa Giardia lamblia, sedangkan gejala ekstraintestinal terjadi pada tahap kronis, terlihat antara waktu 3 bulan sampai 4 hari pasca investasi protozoa (Mauludyahwati et al., 2018).

Fase akut biasanya dimulai dengan gejala gastrointestinal berupa mual dan muntah. Fase akut giardiasis berlangsung 3 4 hari dan fase kronik berlangsung selama dua tahun atau lebih ditandai dengan penurunan berat badan akibat diare intermitten sehingga menyebabkan malabsorbsi (Harun, Sennang dan Rusli, 2019).

Untuk mengetahui prevalensi giardiasis dan kondisi hygiene perorangandan pada anak usia dini, dilakukan survai pada murid PAUD (Pendidikan Anak Usia Dini) di KB-TK Al Amin Paciran Lamongan. Diharapkan dengan adanya penelitian ini dapat menjadi dasar penting dalam menanggulangi dan mencegah kejadian giardiasis pada anak usia dini. Artikel ini ditulis untuk menyajikan gambaran kejadian giardiasis pada PAUD (Pendidikan Anak Usia Dini) di KB-TK Al Amin Paciran Lamongan. 


\section{BAHAN DAN CARA}

Jenis penelitian ini merupakan penelitian observasional deskriptif dimana hanya menggambarkan hasil penelitian dengan menggunakan desain cross sectional (potong lintang). Variabel dependen dalam penelitian ini adalah kejadian giardiasis pada murid PAUD (Pendidikan Anak Usia Dini), variabel independen yaitu hygiene perorangan yang meliputi kebersihan kuku, kebiasaan mencuci tangan, kebiasaan menggunakan alas kaki dan kebiasaan buang air besar.

Populasi penelitian adalah seluruh KB-TK PAUD di Lamongan dan sampel penelitian adalah KB-TK Al Amin Paciran Lamongan yang memenuhi kriteria inklusi sampel. Kriteria inklusi sampel adalah Murid PAUD dengan rentang usia 2 - 6 tahun, dan orangtua anak/wali murid setuju ikut dalam penelitian dengan menandatangani informed concent. Sedangkan kriteria eksklusi sampel adalah anak dengan usia rentang 2 - 6 tahun dan orangtua anak/wali tidak mau ikut dalam penelitian dan tidak memungkinkan untuk dilakukan pengambilan tinja anak. Jumlah sampel penelitian ini sebesar 61 anak. Sebelum proses pengambilan data anak, orangtua anak/wali diminta untuk menandatangani informed consent bersedia dan setuju mengikuti penelitian ini. Penentuan kejadian giardiasis ditegakkan melalui pemeriksaan tinja untuk menemukan kista Giardia lamblia dalam feses, pemeriksaan dilakukan di laboratorium Rumah Sakit Dr.Soetomo. Sampel tinja dibawa dari Lamongan ke RS. Dr. Soetomo menggunakan media transport yang diberi es sebagai pengawet sementara (cool box) dengan wadah yang tertutup rapat. Pemeriksaan tinja dilakukan dengan cara pewarnaan langsung dengan eosin $2 \%$. Data hygiene perorangan diperoleh melalui wawancara dengan kuesioner yang telah disiapkan. Analisis korelasi data dilakukan secara deskriptif dengan menggunakan $C h i$ Square Fisher Exact Test dimana nilai Odds Ratio (OR) yang dihitung berdasarkan nilai OR pada sampel berukuran kecil (Valenzuela C, 1993).

\section{HASIL}

Kejadian murid PAUD yang positif Giardiasis yaitu sebanyak 5 anak $(8,2 \%)$. Distribusi kejadian giardiasis dapat dilihat dalam Tabel 1 berikut

Tabel 1. Distribusi Kejadian Giardiasis Murid di KB-TK Al Amin Paciran Lamongan, Jawa Timur

\begin{tabular}{lrr}
\hline \multicolumn{1}{c}{ Giardiasis } & \multicolumn{1}{c}{ N } & \multicolumn{1}{c}{$\%$} \\
\hline Positif & 5 & 8,2 \\
Negatif & 56 & 91,8 \\
\hline Total & 61 & 100,0 \\
\hline
\end{tabular}

Tabel 2 menyajikan gambaran hygiene perorangan pada murid $\mathrm{KB}-\mathrm{TK} \mathrm{Al}$ Amin Paciran Lamongan dengan melihat beberapa faktor lingkungan yang berhubungan dengan kejadian Giardiasis. Sebanyak 23 anak $(37,7 \%)$ mempunyai kebersihan kuku yang kurang baik, 27 anak $(44,3 \%)$ mempunyai kebiasaan mencuci tangan yang kurang baik, sebanyak 11 anak (18\%) mempunyai kebiasaan menggunakan alas kaki yang kurang baik, dan 22 anak $(36,1 \%)$ mempunyai kebiasaan buang air besar sembarangan. Kebiasaan kurang baik terbanyak terlihat pada kebiasaan mencuci tangan dan terkecil pada kebiasaan menggunakan alas kaki.

Tabel 2. Distribusi Hygiene Perorangan Murid di KB-TK Al Amin Paciran Lamongan, Jawa Timur

\begin{tabular}{lcccccc}
\hline \multirow{2}{*}{\multicolumn{1}{c}{ Variabel }} & \multicolumn{2}{c}{ Kurang Baik } & \multicolumn{2}{c}{ Baik } & \multicolumn{2}{c}{ Total } \\
\cline { 2 - 7 } & $\mathrm{n}$ & $\%$ & $\mathrm{n}$ & $\%$ & $\mathrm{~N}$ & $\%$ \\
\hline Kebersihan kuku & 23 & 37,7 & 38 & 62,3 & 61 & 100 \\
$\begin{array}{l}\text { Kebiasaan mencuci } \\
\text { tangan }\end{array}$ & 27 & 44,3 & 34 & 55,7 & 61 & 100 \\
$\begin{array}{l}\text { Kebiasaan menggunakan } \\
\text { alas kaki }\end{array}$ & 11 & 18,0 & 50 & 82,0 & 61 & 100 \\
Kebiasaan buang air besar & 22 & 36,1 & 39 & 63,9 & 61 & 100 \\
\hline
\end{tabular}


Tabulasi silang antara kejadian giardiasis dan hygiene perorangan murid di KB-TK Al Amin Paciran Lamongan, dapat dilihat dalam Tabel 3. Tabulasi silang ini juga digunakan sebagai dasar dalam perhitungan Odds Ratio (OR) untuk melihat gambaran risiko terjadinya giardiasis pada dua kelompok dengan hygiene perorangan yang berbeda.

Pada Tabel 3 dapat terlihat bahwa murid yang tidak terinfeksi Giardia lamblia, adalah murid yang baik kebersihan kuku (67,9\%), kebiasaan baik dalam mencuci tangan (58,9\%), kebiasaan menggunakan alas kaki dengan baik $(89,3 \%)$, dan kebiasaan baik dalam melakukan buang air besar $(69,6 \%)$ (Tabel 3).

Risiko terjadinya giardiasis didapatkan pada murid dengan kebiasaan menggunakan alas kaki kurang baik mempunyai risiko 43,71 kali lebih besar untuk terkena giardiasis. Sedangkan risiko terkecil didapatkan pada kebiasaan mencuci tangan yang kurang baik dimana hanya mempunyai risiko 5,73 kali untuk terkena giardiasis.

Tabel 3. Distribusi Kejadian Giardiasis yang Berkaitan dengan Hygiene Perorangan Murid di KB-TK Al Amin Paciran Lamongan, Jawa Timur

\begin{tabular}{|c|c|c|c|}
\hline \multirow{2}{*}{ Variabel } & \multicolumn{2}{|c|}{ Giardiasis } & \multirow{2}{*}{ OR $(95 \% \mathrm{CI})$} \\
\hline & Positif & Negatif & \\
\hline \multicolumn{4}{|l|}{ Kebersihan kuku } \\
\hline Kurang baik & $5(100 \%)$ & $18(32,1 \%)$ & 12,31 \\
\hline Baik & $0(0 \%)$ & $38(67,9 \%)$ & $(95 \%$ CI, 1,29-580,49) \\
\hline \multicolumn{4}{|c|}{ Kebiasaan mencuci tangan } \\
\hline Kurang baik & $4(80 \%)$ & $23(41,1 \%)$ & 5,73 \\
\hline Baik & $1(20 \%)$ & $33(58,9 \%)$ & $(95 \%$ CI, 0,5-290,96) \\
\hline \multirow{2}{*}{\multicolumn{4}{|c|}{$\begin{array}{l}\text { Kebiasaan menggunakan alas } \\
\text { kaki }\end{array}$}} \\
\hline & & & \\
\hline Kurang baik & $5(100 \%)$ & $6(10,7 \%)$ & 43,71 \\
\hline Baik & $0(0 \%)$ & $50(89,3 \%)$ & $(95 \%$ CI, 3,98 - 2046,9) \\
\hline \multicolumn{4}{|c|}{ Kebiasaan buang air besar } \\
\hline Kurang baik & $5(100 \%)$ & $17(30,4 \%)$ & 13,33 \\
\hline Baik & $0(0 \%)$ & $39(69,6 \%)$ & $(95 \%$ CI, 1,40-628,05) \\
\hline
\end{tabular}

\section{PEMBAHASAN}

Prevalensi giardiasis di KB-TK Al Amin didapatkan sebesar $8,2 \%$. Prevalensi ini lebih tinggi dari hasil penelitian Diarthini dkk (2018) di Desa Dukuh Kabupaten Karangasem, Bali dimana prevalensi infeksi parasit usus didapatkan sebesar 3\% (Diarthini et al., 2018). Hasil penelitian Darlan et al pada anak sekolah di Medan diperoleh prevalensi sebesar 4,5\% (Darlan et al., 2018).

Namun prevalensi giardiasis di KBTK Al Amin lebih rendah daripada hasil penelitian oleh Campbell et al pada masyarakat pedesaan Timor Leste dengan prevalensi infeksi parasit usus sebesar 13\% (Campbell et al., 2016). Hasil penelitian Chin et al yang dilakukan di Malaysia memperoleh prevalensi sebesar 14,2\% (Chin et al., 2016). Penelitian yang dilakukan oleh Al-Mekhlafi et al pada masyarakat pedesaan Sana'a
Yaman menunjukan prevalensi infeksi parasit usus sebesar 16,1\% (Al-Mekhlafi et al., 2016). Selain itu, hasil penelitian Suliman et al pada anak sekolah didapatkan prevalensi sebesar 22,9\% (Suliman et al., 2019). Hasil penelitian ini juga lebih rendah dibandingkan dengan penelitian oleh Artika et al prevalensi giardiasis diperoleh sebesar 22\% di SDN 14 Olo Kecamatan Padang Barat, Kota Padang (Artika, Nurhayati and Alioes, 2017). Pada penelitian Arindatta et al menyebutkan prevalensi giardiasis sebesar 31,1\% di Pulau Mandangin, Sampang Jawa Timur (Arindata, Prasetyo dan Budiono, 2017). Hasil penelitian Bachtiar di Pulau Mandangin, Sampang, Jawa Timur dan Kelurahan Mojo, Kota Surabaya terdapat prevalensi sebesar 28,9\% di Pulau Mandangin sedangkan di Kelurahan Mojo sebesar 1,8\% (Bachtiar, 2018). Bila dilihat dari hasil beberapa 
penelitian tersebut, perbedaan prevalensi yang cukup signifikan ini dapat disebabkan beberapa faktor antara lain hygiene perorangan, sanitasi lingkungan, serta kondisi social ekonomi yang rendah, umur, status gizi, imunitas, dan infeksi parasit usus yang lain.

Pada variabel hygiene perorangan menunjukkan sebagian besar anak mempunyai hygiene perorangan yang baik. Dapat dilihat pada Tabel 2 bahwa persentase hygiene perorangan yang kurang baik lebih rendah yaitu $37,7 \%$ anak mempunyai kebersihan kuku yang kurang baik, 44,3\% mempunyai kebiasaan mencuci tangan yang kurang baik, $18 \%$ mempunyai kebiasaan menggunakan alas kaki yang kurang baik, serta $36,1 \%$ mempunyai kebiasaan buang air besar sembarangan. Hal ini sejalan dengan penelitian oleh Campbell et al pada anak prasekolah di Timor Leste dimana hanya 31\% anak menggunakan alas kaki saat berada diluar rumah (Campbell et al., 2016). Lain halnya dengan hasil penelitian Al-Mekhlafi et al, prevalensi hygiene perorangan anak sekolah di Yaman yang kurang baik lebih tinggi yaitu sebanyak 54,8\% anak tidak mencuci tangan dengan sabun dan 65,5\% anak tidak menggunting kuku (Al-Mekhlafi et al., 2016).

Untuk kaitan antara hygiene perorangan dengan kejadian giardiasis dalam Tabel 3 dapat terlihat bahwa seluruh murid $(100 \%)$ dengan giardiasis mempunyai kebersihan kuku yang kurang baik, kebiasaan menggunakan alas kaki kurang baik dan mempunyai kebiasaan buang air besar sembarangan, sedangkan murid dengan kebiasaan mencuci tangan yang kurang baik dan menderita giardiasis sebesar $80 \%$. Bila dibandingkan dengan murid yang tidak terinfeksi Giardia lamblia, murid dengan kebiasaan baik (kebersihan kuku 67,9\%, kebiasaan mencuci tangan 58,9\%, kebiasaan menggunakan alas kaki 89,3\%, serta kebiasaan buang air besar 69,6\%) persentasenya lebih banyak dibandingkan murid dengan kebiasaan kurang baik.

Kondisi hygiene perorangan berkaitan erat dengan kejadian giardiasis karena kurangnya kebersihan diri dapat mempermudah kista Giardia lamblia masuk kedalam saluran pencernaan sehingga menyebabkan infeksi. Umumnya pada anakanak penularan terjadi melalui fecal oral. Anak-anak dianggap masih kurang memahami dan belum bias menjaga kebersihan diri sehingga rentan terkena infeksi giardiasis.

Kemudian pada hasil perhitungan Odds Ratio (OR) diperoleh murid dengan kebersihan kuku kurang baik mempunyai risiko 12,31 kali lebih besar untuk terkena giardiasis, murid dengan kebiasaan mencuci tangan yang kurang baik mempunyai risiko 5,73 kali lebih besar untuk terkena giardiasis, murid dengan kebiasaan menggunakan alas kaki kurang baik mempunyai risiko 43,71 kali lebih besar untuk terkena giardiasis, dan murid dengan kebiasaan buang air besar sembarangan mempunyai risiko 13,33 kali lebih besar untuk terkena giardiasis dibandingkan dengan murid yang mempunyai kebiasaan (hygiene perorangan) yang baik. Penelitian ini sejalan dengan penelitian Artika et al yaitu terdapat hubungan yang signifikan antara kebiasaan mencuci tangan dengan kejadian giardiasis ( $<<0,001)$, akan tetapi tidak ada hubungan yang signifikan antara kebiasaan memotong kuku dengan kejadian giardiasis ( $>00,05$ ). Meskipun demikian dalam penelitian tersebut, proporsi murid yang terkena giardiasis lebih banyak yang mempunyai kebiasaan memotong kuku yang kurang baik dibandingkan dengan yang baik (34,6\%:13,5\%) (Artika, Nurhayati and Alioes, 2017). Pada penelitian oleh Suliman et al didapatkan hubungan signifikan antara infeksi parasit usus dan kebiasaan mencuci tangan ( $\mathrm{p}=0,0035)$ (Suliman et al., 2019). Pada penelitian Al-Mekhlafi et al terdapat hubungan yang signifikan antara infeksi Giardia lamblia dengan kebiasaan memotong kuku (p<0,001) (Al-Mekhlafi et al., 2016). Penelitian ini juga sejalan dengan penelitian Bachtiar, yang menyebutkan penyebab perbedaan prevalensi giardiasis antara murid SD di Pulau Mandangin, Sampang dibandingkan dengan Kelurahan Mojo, Kota Surabaya, yaitu kebiasaan buang air besar murid, kebiasaan bermain murid, dan sumber air bersih yang digunakan sehari-hari (Bachtiar, 2018). 


\section{KESIMPULAN DAN SARAN}

\section{Kesimpulan}

Kejadian giardiasis pada 61 murid PAUD di KB-TK Al Amin Paciran Lamongan sebesar 8,2\% atau 5 dari 61 anak usia 2 - 6 tahun. Seluruh murid (100\%) dengan giardiasis mempunyai kebersihan kuku yang kurang baik, kebiasaan menggunakan alas kaki kurang baik dan mempunyai kebiasaan buang air besar sembarangan. Sebanyak $80 \%$ murid dengan giardiasis mempunyai kebiasaan mencuci tangan yang kurang baik. Dari hasil perhitungan Odds Ratio (OR) diperoleh murid dengan kebiasaan menggunakan alas kaki kurang baik mempunyai risiko 43,71 kali lebih besar untuk terkena giardiasis, murid dengan kebiasaan buang air besar sembarangan mempunyai risiko 13,33 kali lebih besar untuk terkena giardiasis, murid dengan kebersihan kuku kurang baik mempunyai risiko 12,31 kali lebih besar untuk terkena giardiasis dan murid dengan kebiasaan mencuci tangan yang kurang baik mempunyai risiko 5,73 kali lebih besar untuk terkena giardiasis.

\section{Saran}

Pengawasan orangtua untuk mengajarkan dan membiasakan anakanaksupaya memahami dan berperilaku hidup sehat sangat dianjurkan, antara lain menggunakan alas kaki ketika bermain di tanah, membiasakan buang air besar di jamban, menjaga kebersihan kuku dan mencuci tangan dengan air mengalir serta sabun sebelum makan atau setelah buang air besar.

\section{UCAPAN TERIMA KASIH}

Ucapan terima kasih disampaikan kepada pihak laboratorium Rumah Sakit Dr. Soetomo, juga kepada para guru dan orangtua murid KB-TK Al Amin Paciran Lamongan.

\section{DAFTAR PUSTAKA}

Al-Mekhlafi, A. M. et al. (2016) 'School-based Prevalence of Intestinal Parasitic Infections and Associated Risk Factors in Rural Communities of Sana'a, Yemen', Acta Tropica. Elsevier B.V., 163, pp. 135-141. doi: 10.1016/j.actatropica.2016.08.009.

Anzani, B. P. and Saftarina, F. (2019) 'Penatalaksanaan Diare pada Anak Usia 2 Tahun dengan Pendekatan Kedokteran Keluarga Management Of Diarrhea in Childern 2 Years with Family Medicine Approach', Majority, 8, pp. 24-31.

Arindata, A. N., Prasetyo, R. H. and Budiono (2017) Faktor Risiko Giardiasis pada Siswa Sekolah Dasar Negeri Pulau Mandangin 06, Kecamatan Sampang, Kabupaten Sampang, Jawa Timur. Universitas Airlangga.

Artika, M., Nurhayati and Alioes, Y. (2017) 'Hubungan Kebiasaan Mencuci Tangan dan Memotong Kuku dengan Kejadian Giardiasis Asimtomatik', Jurnal Kesehatan Andalas, 6(1), p. 70. doi: 10.25077/jka.v6i1.647.

Bachtiar, Z. A. (2018) Perbandingan Prevalensi Giardiasis dan Status Gizi Anak pada Daerah dengan Akses Jamban Sehat Kurang Memadai dan Memadai. Universitas Airlangga.

Bartelt, L. A. and Sartor, R. B. (2015) 'Advances in Understanding Giardia: Determinants and Mechanisms of Chronic Sequelae', F1000Prime Reports, 7(62).

Campbell, S. J. et al. (2016) 'Water, Sanitation and Hygiene Related Risk Factors for SoilTransmitted Helminth and Giardia Duodenalis Infections in Rural Communities in Timor-Leste', International Journal for Parasitology, 46(12), pp. 771-779. doi: 10.1016/j.ijpara.2016.07.005.

Centers for Disease Control and Prevention (2015) Giardia.

Chin, Y. T. et al. (2016) 'Prevalence and Risk Factors of Intestinal Parasitism Among Two Indigenous Sub-ethnic Groups in Peninsular Malaysia', Infectious Diseases of Poverty. Infectious Diseases of Poverty, 5(1). doi: 10.1186/s40249-016-0168-z.

Darlan, D. M. et al. (2018) 'Correlation Between Iron Deficiency Anemia and Intestinal Parasitic Infection in School-Age Children in Medan', IOP Conference Series: Earth and Environmental Science, 125(1), pp. 4-10. doi: 10.1088/1755-1315/125/1/012059.

Diarthini, N. L. P. E. et al. (2018) 'Blastocystis and Other Intestinal Parasites Infections in Elementary School Children in Dukuh Village, Karangasem District, Bali, Indonesian Journal of Tropical and Infectious Disease, 7(3), p. 57. doi: 10.20473/ijtid.v7i3.7323.

Halliez, M. C. M. and Buret, A. G. (2013) 'Extraintestinal and Long Term Consequences of Giardia Duodenalis Infections', World 
Journal of Gastroenterology, 19(47), pp. 8974-8985. doi: 10.3748/wjg.v19.i47.8974.

Harun, H., Sennang, N. and Rusli, B. (2019) 'Giardiasis', Healthy Tadulako Journal, 5(3), pp. $1-80$.

Ivanov, A. I. (2010) 'Giardia and Giardiasis', Bulgarian Journal of Veterinary Medicine, 13(2), pp. 65-80.

Kementerian Kesehatan RI Badan Penelitian dan Pengembangan (2018) 'Hasil Utama Riset Kesehatan Dasar', Kementrian Kesehatan Republik Indonesia, pp. 1-100. doi: 1 Desember 2013.

Leung, A. K. C. et al. (2019) 'Giardiasis: an Overview.', Recent Patents on Inflammation \& Allergy Drug Discovery, 13(2). doi: 10.2174/1872213x13666190618124901.

Mauludyahwati, L. et al. (2018) 'Manifestasi Ekstraintestinal Giardiasis : Reactive Arthritis Manifestasi Ekstraintestinal Giardiasis : Reactive Arthritis', (March).
Ramadhan, M. A. (2019) Prevalensi dan Faktor Giardiasis pada Siswa Sekolah Dasar di Kelurahan Tanah Kali Kedinding, Surabaya. Universitas Airlangga.

Saraswati, A. M. and Nurdian, Y. (2018) 'Anemia in the Children of Migratory Farm Workers that Infested By Giardia intestinalis', (May), pp. 7-10.

Suliman, M. A. et al. (2019) 'Prevalence of Intestinal Parasitic Infections and Associated Risk Factors among School Children in White Nile State, Sudan Toxoplasmosis View project schistosomiasis View project Prevalence of Intestinal Parasitic Infections and Associated Risk Factors am', Journal of Infectious Disease and Diagnosis, 4(1), pp. 8-11. doi: 10.4172/2576-389X.1000125.

Valenzuela C (1993) 'Dos Soluciones Para la Estimacion de "Odds Ratios" Con Ceros [2 Solutions for Estimating Odds Ratios with Zeros]', Rev Med Chil, 121(12), pp. 1441-4. 